CASE REPORTS

\title{
Transient erythroid hypoplasia in a patient on long-term co-trimoxazole therapy
}

\author{
M. Elizabeth M. STEPhenS \\ M.A., M.B., M.R.C.P. \\ Department of Gastroenterology, Central Middlesex Hospital, London
}

Summary

The occurrence of isolated erythroid hypoplasia in a patient on long-term treatment with co-trimoxazole is described. It is suggested that this haematological complication, which has not been previously reported, was due to hypersensitivity to the sulphonamide component.

\section{Introduction}

Although co-trimoxazole ('Septrin', 'Bactrim') is in common use, the incidence of associated erythropoietic disturbance is low. This is surprising, since the trimethoprim component has been shown to have some action on human dihydrofolate reductase (Hitchings, 1969) and the sulphamethoxazole might be expected to cause haematological complications as do other sulphonamides (Laurence, 1966).

It therefore seemed of interest to report this case of red cell hypoplasia, probably attributable to an immunological reaction to the sulphamethoxazole.

\section{Case report}

The patient, a 53-year-old housewife, had in 1964 undergone total colectomy and ileo-rectal anastamosis because of a 5-year history of diarrhoea and abdominal pain due to Crohn's disease. Four years later, persistence of her symptoms led to removal of her terminal ileum. Unfortunately her diarrhoea continued despite various symptomatic measures, subsequent investigations revealing mild steatorrhoea. Treatment of an attack of pleurisy in February 1970 with co-trimoxazole ( 2 tablets twice a day) produced a marked clinical improvement, her frequency of bowel action diminishing from $10-20$ to 6-7 times per $24 \mathrm{hr}$ and therapy was therefore continued, with sustained benefit. Sixteen months later, she developed symptoms suggestive of anaemia and was subsequently found to have a $\mathrm{Hb}$ of $7 \cdot 1 \mathrm{~g} \%$ (her $\mathrm{Hb}$ having been $11.7 \%$ in March 1971) and to be in mild heart failure. Co-trimoxazole was discontinued, antifailure therapy instituted and she was admitted for full investigation and treatment. The other drugs she had received during the previous 2 years were diphenoxylate ('Lomotil'), codeine phosphate, Multivite, Calcium Sandoz, effervescent potassium, folic acid, vitamin $B_{12}$ and Mandrax.

The results of investigations were as follows. Hb $5.4 \mathrm{~g} \%$, PCV 17\%, MCV $103 \mu^{3}$, MCHC 31.4 , WBC $5800(77 \%$ neutrophils, $19 \%$ lymphocytes, $4 \%$ monocytes), platelets $194,000 / \mathrm{mm}^{3}$, film-anisocytosis, poikilocytosis and oval macrocytes (no Heinz bodies seen). Reticulocyte count $1.0 \%$, ESR $95 \mathrm{~mm} /$ hr. Bone marrow (sternum and iliac crest); erythroid elements reduced, maturation normoblastic with some evidence of dyserythropoiesis; granulocyte numbers and maturation normal (no giant metamyelocytes seen); lymphocytes, plasma cells and reticulum cells all slightly increased (probably only relatively); appearances 'suggestive of red cell hypoplasia ? drug induced'. Bone marrow trephine; 'picture of depression of normoblastic series, a drug reaction being the most likely cause'. Serum folate $6.2 \mathrm{ng} / \mathrm{ml}$; serum $B_{12} 250 \mu \mathrm{eg} / \mathrm{ml}$; serum iron 240 $\mu \mathrm{g} / \mathrm{ml}$; total iron binding capacity $288 \mu \mathrm{g} / \mathrm{ml}$; Ham's test negative; serum bilirubin $0.3 \mathrm{mg} \%$.

As there was no evidence of spontaneous recovery of her marrow erythroid hypoplasia after 3 weeks, she was transfused 3 pints of blood and started on oxymethalone $50 \mathrm{mg}$ b.d. She required one further blood transfusion, but 6 months after cessation of cotrimoxazole, she had fully recovered, her $\mathrm{Hb}$ being $12.1 \mathrm{~g} \%$, with WBC 8200 and ESR persistently raised at $92 \mathrm{~mm} / \mathrm{hr}$ (presumed due to bowel disease).

Within 3 months of stopping co-trimoxazole, her diarrhoea had become as bad as ever again and it was decided to try her on another antibiotic, in the form of Ampicillin $250 \mathrm{mg}$ b.d. After a further 3 months, her bowel habit had improved significantly. 


\section{Discussion}

Trimethoprim [2,4-diamino-5-(3,4,5-trimethoxybenzyl) pyrimidine], related to the antimalarial drug pyrimethamine, competitively inhibits dihydrofolate reductase (Roth et al., 1962), thus blocking conversion of dihydrofolic to tetrahydrofolic acid, the precursor of the coenzyme forms of folate involved in purine synthesis. Due to species differences in physical structure and perhaps amino-acid sequence, the bacterial enzyme is some 50,000 times more sensitive than its mammalian counterpart (Hitchings, 1969), hence the therapeutic use of trimethoprim. Some workers (Chanarin and England, 1972) have even suggested that mammalian dihydrofolate reductase is unaffected by trimethoprim and that the latter has some other mode of action. Sulphamethoxazole, like all sulphonamides, competes with para-aminobenzoic acid in bacterial folic acid synthesis, man being immune, as he uses dietary folate and does not synthesize folic acid. It may have additional as yet unelucidated actions (Stephens, 1973). Although the individual drugs are only bacteriostatic, the combination is synergistic, its action being bacteriocidal (Darrel, Garrod and Waterworth, 1968; Bushby and Hitchings, 1968).

Haematological complications of therapy have not been many, considering the large number of patients treated with co-trimoxazole. Granulocytopenia and/or leucopenia (Dawson and Routledge, 1971; Evans and Tell, 1969; Hanley, 1969; Hulme and Reeves, 1971; Kahn, Fein and Brodsky, 1968; McCarthy, 1969; McPherson and Raik, 1970; Mohan, 1969; Palva and Koivisto, 1971; Paulley, 1970), sometimes after only short courses of the drug and thrombocytopenia (Hanley, 1969; Hammett, 1970; Kahn et al., 1968; McPherson and Raik, 1970; Mohan, 1969; Paulley, 1970) are now well recognized complications (all cases have recovered spontaneously).

Anaemia has only rarely been reported, however, Kahn and his colleagues (1968) described one case of mild anaemia in a patient on long-term high-dosage co-trioxazole therapy, but as marrow examination was not performed, the cause remains uncertain. It is, however, of note that one subject treated for only 2 weeks with trimethoprim alone developed anaemia with transitional megaloblastic change on marrow examination, although the serum folate remained normal, while the leucopenia and thrombocytopenia of another patient in their long-term study disappeared on treatment with folinic acid ('citrovorum factor' or 5-methylfolic acid, viz. reduced folate), although co-trimoxazole therapy continued, suggesting impairment of folate utilization due to trimethoprim via its action on dihydrofolate reductase. Jewkes, Edwards and Grant (1971) reported in detail a patient who developed megaloblastic ery- thropoiesis 6 months after starting the currently $\stackrel{\$}{\varnothing}$ recommended dose of trimethoprim $320 \mathrm{mg}$ com- $c$. bined with sulphamethoxazole $1600 \mathrm{mg}$ daily, to $\vec{\Rightarrow}$ suppress bronchial infection. Folic acid therapy was of no avail, but there was a dramatic response to folinic acid, again indicating a block in folate metabolism at the level of dihydrofolate reductase.

McPherson and Raik (1970) and more recently $\stackrel{\varnothing}{\varrho}$ Dawson and Routledge (1971) documented cases of pancytopenia associated with megaloblastic erythro- $\vec{\circ}$ poiesis following co-trimoxazole therapy, which both recovered haematologically after therapy was dis- $\vec{\omega}$ continued (McPherson and Raik also gave their $\frac{\sigma}{\circ}$ patient folinic acid). Dawson and Routledge's patient $\frac{\mathbb{C}}{3}$ had low serum and red cell folate levels and it seems 3 . likely that the cause of anaemia in both cases was of interference by trimethoprim with folate metabolism. ON

One instance of aplastic anaemia complicating co- N

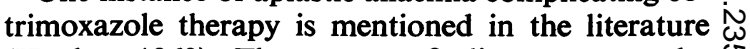
(Hanley, 1969). The marrow findings are not de- $G$ scribed and it is possible that the sulphmethoxazole $\frac{\circ}{工}$ component was the agent responsible.

The case described here had persistently normal $\frac{T}{0}$ white blood cell and platelet counts, the defect being in erythropoiesis only. Detailed marrow studies $\overrightarrow{0}$ indicated that this was due to hypoplasia of red ced precursors probably resulting from drug toxicits there being no evidence of impairment of folato metabolism. Since she finally recovered fully while taking all her usual drugs (anti-diarrhoeals, supplements, etc.) except co-trimoxazole, the latter was $\frac{\circ}{\Phi}$ thought to be the drug responsible. Hypoplastic $\stackrel{\varrho}{\Rightarrow}$ anaemia being a well recognized complication of sulphonamide therapy, it was thought most likely that hers was caused by an immunological reaction to the sulphamethoxazole component of the cotrimoxazole.

The dramatic improvement in her diarrhoea as a result of co-trimoxazole treatment suggested that this symptom was at least in part due to abnormal bacterial activity in the small intestine and it was for this reason that a trial of an alternative antibiotic was commenced.

\section{Acknowledgments}

I am very grateful to Sir Francis Avery-Jones, under whose care this patient was admitted, for permission to publish the case and for his helpful comments. I should also like to thank N Dr Parker-Williams for advising on the haematological diagnosis and management.

\section{References}

Bushby, S.R.M. \& Hitchings, G.H. (1968) Trimethoprim, a sulphonamide potentiator. British Journal of Pharmacology and Chemotherapy, 33, 72.

Chanarin, I. \& ENGLAND, J.M. (1972) Toxicity of trimetho- ? prim-sulphamethoxazole in patients with megaloblastic $\mathbb{Q}$ haemopoiesis. British Medical Journal, 1, 651 . 
Darrel, J.H., Garrod, L.P. \& Waterworth, P.M. (1968) Trimethoprim: laboratory and clinical studies. Journal of Clinical Pathology, 21, 202.

Dawson, D.W. \& Routledge, R.C. (1971) Trimethoprim and sulphamethoxazole. British Medical Journal, 4, 364.

Evans, D.I.K. \& Tell, R. (1969) Agranulocytosis after trimethoprim and sulphamethoxazole. British Medical Journal, 1, 578.

Hammett, J.F. (1970) Thrombocytopenia following administration of 'Bactrim'. Medical Journal of Australia, 2, 200.

HANLEY, T. (1969) In: Discussion of Treatment of Gonorrhoea with Sulphamethoxazole (Ed. by C. B. S. Schofield, G. Masterson, M. Moffett and M. T. McGill). Postgraduate Medical Journal, 45, November Supplement, p. 84.

Hitchings, G.H. (1969) Species differences among dihydrofolate reductases as a basis for chemotherapy. Postgraduate Medical Journal, 45, November Supplement, p. 7.

Hulme, B. \& ReEves, D.S. (1971) Leucopenia associated with trimethoprim-sulphamethoxazole after renal transplantation. British Medical Journal, 3, 610.

JewKes, R.F., EDWARDS, M.S. \& GRANT, B.J.B. (1971) Haematological changes in a patient on long-term treatment with a trimethoprim-sulphonamide combination. Postgraduate Medical Journal, 46, 723.
Kahn, S.B., Fein, S.A. \& Brodsky, I. (1968) Effects of trimethoprim on folate metabolism in man. Clinical Pharmacology and Therapeutics, 9, 550.

LAURenCe, D.R. (1966) Clinical Pharmacology, 3rd edn., p. 68. Churchill: London.

MCCARTHY, O.R. (1969) Neutropenia after trimethoprimsulphamethoxazole for bronchitis. British Medical Journal, 3, 113.

MCPherson, V.J. \& RAIK, E. (1970) Thrombocytopenia following administration of 'Septrin'. Medical Journal of Australia, 2, 754.

Moнan, P. (1969) Thrombocytopenia and agranulocytosis following 'Septrin'. Practitioner, 202, 553.

Palva, I.P. \& KoIvisto, O. (1971) Agranulocytosis associated with trimethoprim-sulphamethoxazole. British Medical Journai, 4, 301.

Paulley, J.W. (1970) Drug neutropenia. British Medical Journal, 2, 364.

Roth, B., Falco, E.A., Hitchings, G.H. \& Bushby, S.R.M. (1962) 5-benzyl-2,4 diaminopyrimidines as bacterial agents. I. Synthesis and antibacterial activity in vitro. Journal of Medical and Pharmaceutical Chemistry, 5, 1103.

STEPHENS, M.E.M. (1973) Effect of co-trimoxazole on phenylalanine metabolism. Lancet, i, 549.

\section{Infantile nephrotic syndrome}

\author{
N. A. NAGI \\ M.B., CH.B., M.M.Sc. \\ Department of Paediatrics, \\ University of Mosul, Iraq
}

\section{Summary}

Four infants, two boys and two girls, with congenital nephrotic syndrome are reported in a single family. The disease process began during the first year of life. The disorder did not respond to corticosteroid therapy. One infant received cyclophosphamide therapy as well without avail. All four children died from intercurrent infection. The family tree is suggestive of an autosomal recessive inheritance.

\section{Introduction}

In the reported series of the nephrotic syndrome in childhood, only $1-5 \%$ of the cases occur in the first year of life (Barnett, Forman and Lauson, 1952; Arneil, 1961; Cornfield and Schwartz, 1966; McDonald, Wiggelinkhuizen and Kashula, 1971). A familial incidence has been recorded among these infants (Vernier, Brunson and Good, 1957; Parker and Piel, 1960; Hansen and Coye, 1961; Cornfield

\author{
L. NOURI \\ M.B., CH.B., M.R.C.P., D.C.H.
}

\author{
Department of Paediatrics, \\ University of Baghdad, Iraq
}

and Schwariz, 1966). The term 'congenital nephrosis' was used to describe the condition starting in the first few weeks of life.

Norio, Hjolt and Hallman (1964) and Norio (1966) in extensive studies of congenital nephrosis came to the conclusion that the disorder is a hereditary one, transmitted in an autosomal recessive way and is much more common in Finland than in other countries.

The Finnish workers described the main features of the syndrome as premature birth, large placenta, distended abdomen, proteinuria and dysproteinaemia of the nephrotic type, high susceptibility to infection together with resistance to all therapies and consequently with a fatal outcome.

Hoyer et al. (1967) reported from U.S.A. three siblings with congenital nephrosis belonging to a family of Finnish extraction.

We here report our experience with an Iraqi family of nine children, four of whom died from 